\title{
Coping and Regulatory Responses on Social Media during Health Crisis: a Large-scale Analysis
}

\author{
Olga Abramova \\ University of Potsdam \\ olga.abramova@uni-potsdam.de
}

\author{
Katharina Batzel \\ University of Potsdam \\ katharina.batzel@uni-potsdam.de
}

\author{
Daniela Modesti \\ University of Potsdam \\ daniela.modesti@uni-potsdam.de
}

\begin{abstract}
During a crisis event, social media enables two-way communication and many-to-many information broadcasting, browsing others' posts, publishing own content, and public commenting. These records can deliver valuable insights to approach problematic situations effectively. Our study explores how social media communication can be analyzed to understand the responses to health crises better. Results based on nearly $800 \mathrm{~K}$ tweets indicate that the coping and regulation foci framework holds good explanatory power, with four clusters salient in public reactions: 1) "Understanding" (problem-promotion); 2) "Action planning" (problem-prevention); 3) "Hope" (emotion-promotion) and 4) "Reassurance" (emotionprevention). Second, the inter-temporal analysis shows high volatility of topic proportions and a shift from self-centered to community-centered topics during the course of the event. The insights are beneficial for research on crisis management and practicians who are interested in large-scale monitoring of their audience for well-informed decision-making.
\end{abstract}

\section{Introduction}

Recently social media platforms have become a highly adopted site for crisis communications [1]. Because of many advantages like real-time content, quick interactions, reach information, these information systems can be handy during highly dynamic emergency cases [1][2][51]. By enabling two-way communication and many-to-many information broadcasting, browsing others' posts, publishing own content, and public commenting, such tools facilitate active public engagement during crisis events (e.g., [3]; for review, see [4]).

So far, organizations, such as emergency service agencies, are struggling with the efficient processing of the growing volume of social media data and the management of crisis communication on these platforms [2][6]. As such, policymakers "remain deaf" to those they serve, resulting in offline public protests [5]. Meanwhile, adequate consideration of social media-generated data could deliver valuable insights to effectively approach problematic situations [6][7]. Usually, extreme events (e.g., a terror attack [1], plane crash [2], and outbreak [3]) directly affect a limited group of people, with the majority remaining perceivers who can help victims cope with trauma and return to "normal" life. A vast impact radius increases the issue's complexity disproportionally, which is especially relevant for events with grave psychological and emotional impacts on a worldwide scale (e.g., climate change, war, pandemics) [38]. Past studies report intensive information seeking and sharing on Twitter during the Berlin terrorist attack in 2016 [1], The Sydney Lindt Café Siege in 2014, the Germanwings plane crash in 2015, and the Brussels Terror Attacks in 2016 [2], the 2019 Ebola outbreak [3] and 2009 H1N1 outbreak [40] demonstrating how promising and impactful the scrutiny and understanding social media communications during an extreme event might be [6]. Against the above backdrop, our study aims to explore how social media communication can be analyzed to better understand the responses to crises facilitated by platforms such as Twitter. We ask the following research questions (RQ):

RQ1: Do information exchanges on Twitter reflect a collective response to a crisis event and help us identify coping and regulatory patterns?

RQ2: How do responses change over time?

To answer them empirically, this paper analyzes posts published during the COVID-19 health crisis. Following the advice to stay at home and keep physical distance from peers, a significant part of conversations about the event happens online, for instance, on social network sites (SNS) such as Twitter [8]. Twitter users post tweets to disseminate health information and obtain real-time data [9].

On the theoretical front, past attempts to explain behavior in crisis times widely assumed people 
perform sensemaking [2][10][11] or possibly combine it with terror management [1]. This paper leans on the novel concept of goals associated with information seeking (GAINS), developed by [12]. We propose that social media information exchanges may be interpreted as a way to cope with circumstances perceived as threatening [13]. Applying the wellestablished distinction by [16], we surmise to observe problem- and emotion-focused coping in tweets. Further, regulatory focus theory (RFT) [14] allows to fine-grain the classification, depending on the motivational principle. Two opposed motivational systems can underlie the reactions observed in tweets: users either strive to maximize positive outcomes (promotion focus) or minimize adverse outcomes (prevention focus).

Our results based on nearly 800,000 tweets indicate that the coping and regulation foci framework holds good explanatory power. Second, the intertemporal analysis witnesses high volatility of topic proportions over time. While the cancellation of events comes immediately after the announcement of the pandemic, sound local preventive measures, on the contrary, are only discussed a week after. Third, we observe a shift from self-centered to communityfocused topics through four and a half weeks. As risk perception of the virus changes with time, so do people's behavior and online communication. For this reason, different stakeholders can benefit from our findings, including policymakers, medical staff, and businesses, who are interested in close monitoring of representative large-scale public reactions and concerns. The latter fosters well-informed decisionmaking, inter alia, rapid identification of deviant behavior, and offering tailored mental health support services.

\section{Theoretical background}

To retrieve reactions from information exchanges on social media platforms, it is important to consider the context in which the interactions take place. In the health crisis, penetrating nearly all domains, including family, work, social and economic ones, information exchanges may be perceived as a way of coping with situations that are perceived as threatening [13]. Coping is defined as "constantly changing cognitive and behavioral efforts to manage specific external and/or internal demands that are appraised as taxing or exceeding the resources of the person" [15].

With regard to different foci of coping behavior, a framework that differentiates between problem- and emotion-focused coping is widely acknowledged [16]. Problem-focused strategies aim at tackling and eliminating the problem (i.e., source of the stress) itself. Examples include (but are not limited to) understanding the causes, seeking information or assistance in solving the issue, and making plans of action [17]. Emotion-focused coping aims at managing emotions rather than altering the situation. Typical emotion-focused techniques include distraction (e.g., keeping oneself busy to shift the attention away from the issue), emotional disclosure (e.g., expressing strong emotions about an event), praying and meditation (e.g., for guidance and strength), consuming more food or alcohol, drug therapy and keeping a diary or practicing self-talk [18]. Problem- and emotion-focused coping are not mutually exclusive, and often people use a mixture of several strategies, which may change over time. Research agrees that problem-focused coping is more efficient when the stress's source is potentially under an individual's control; however, when the stress source is beyond the individual's control, emotionfocused efforts are more helpful [17].

Hence, based on this classification, two potential response clusters can be identified in information exchanges on social media during the health crisis: emotion-related and problem-related reactions [15]. One might wonder: Do people, united by common trouble, communicate online because they want to feel better about their problems or because they want to prevent further adverse states? Coping as an effort to optimize problems is consonant with the hedonic principle, which postulates that "people approach pleasure and avoid pain" [14]. Additional consideration of regulatory focus, which indicates the goals individuals pursue when confronted with the respective problem and/or emotion, may further finegrain the understanding of how this principle operates.

Regulatory focus theory (RFT) [14] postulates two motivations to approach the desired states, which either strives to maximize positive outcomes (promotion focus) or to minimize negative outcomes (prevention focus). A promotion focus constitutes selfregulation, which is rooted in nurturance-related needs. It involves a sensitivity to positive outcomes (their presence and absence) through strong ideals, aspirations, and accomplishments. In contrast, a prevention focus addresses security needs and implies a sensitivity to negative outcomes (their absence and presence) through strong thoughts and concerns with protection, safety, and responsibility. RFT has already been successfully applied in the context of health behavior and health message framing (e.g., [19]; [20]; [21]) and online information sharing [22]. Thus, we assume its relevance to capture the individual's online interaction patterns on a health issue.

In our study, together with the problem- vs. emotion-focused messages, we differentiate between 
promotion- and prevention-focused sentiments individuals may express when sharing information during the pandemic. The integration of these two superordinate categorizations into one framework results in a $2 \times 2$ matrix containing four types of online public opinions: problem-promotion, problemprevention, emotion-promotion, and emotionprevention (see Figure 1).

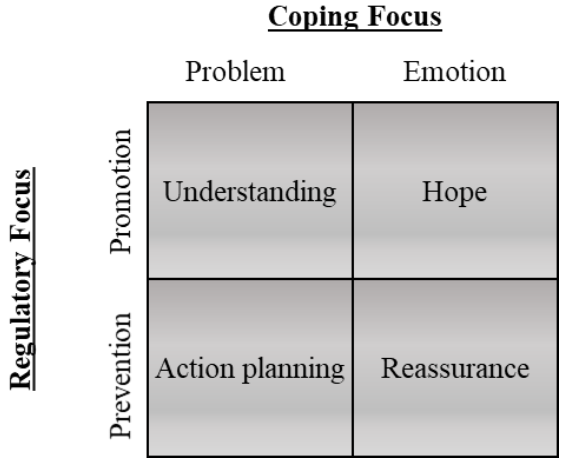

Figure 1. Coping \& regulatory foci framework of information exchanges in a health crisis (adopted from [12]).

The first cluster, problem-promotion, addresses posts to identify the causes and consequences of a problem (i.e., pandemic). It thus deals with the event in a problem-oriented manner by enhancing one's education. Striving to maximize gains from new knowledge, it is also promotion-oriented. We broadly label this group "Understanding," similar to [12]. The second cluster, "Action planning," reflects tangible, situation-adequate courses of action to prevent a further escalation of the problem (i.e., the spread of the infection). It is problem-focused, but unlike the "Understanding" cluster, it is prevention-focused: the goal here is to deal with the crisis via minimizing the likelihood of health deterioration through protective efforts. The third cluster "Hope" reflects personal emotional resources that help to stand the crisis. It is emotion and promotion-focused since it approaches one's emotions via increasing positive emotional states such as hope, gratefulness, solidarity, and trust. "Reassurance" constitutes the fourth cluster, with messages aiming to let negative emotions like anxiety and frustration go. It is emotion- as well as preventionfocused as it deals with emotions via reducing stress.

Altogether, the four clusters that incorporate coping and regulatory focus reflect the public opinions existing in the community faced with a health crisis: understanding, action planning, hope, and reassurance. Besides assigning the tweets into four distinct groups, this categorization also allows for quantifying the coping approaches and the underlying motivations in the community through the calculation of the topics' proportion belonging to each cluster.

\section{Methodology}

We collected data via the web-scraping tool twint [23] and selected tweets by their language. Precisely, public German tweets posted between March 9 and April 9, 2020, were crawled. The start of our research period is marked by the first two COVID-19 ascribed German death cases that were reported on March 9, 2020 [24][25]. April 9, 2020, is the closing date for our research period when for the first time, the negative growth of new active COVID-19 cases in Germany was reported.

Tweets' selection was undertaken with great care. Initially, hashtags were extracted from three different literature outlets [26][27][28]. To verify them, a twoday scrape on the tag \#Corona was conducted on the first day (March 9, 2020) and the last day (April 9, 2020) of the research period. The obtained Twitter samples, 2,995 tweets for March 9, 2020, and 6,497 tweets for April 9, 2020, were inspected by two researchers for hashtags to approve or disprove the tags collected from the literature. As selection criteria, we propose the following: relevant hashtags should be mentioned in one literature outlet and appear in at least five percent of the scraped tweets or be mentioned in at least two different literature outlets. In total, seven tags (\#Corona, \#CoronaVirus, \#CoronaVirusDE, \#CoronaVirusDeutschland, \#Covid-19, \#Covid19, \#Flattenthecurve) were chosen.

Overall a sample of 742,467 unique tweets containing text was obtained implementing the restrictions on language, time, and hashtags described above. On average, 23,202 tweets were posted daily. Most tweets occurred between March 13 and March 23, 2020 (Figure 2). We identified three outliers where tweeting behavior exceeded the usual frequency March 13, March 23, and April 8, 2020. On March 13, a Friday, most German federal states shut down schools and daycare centers as the first restrictive measure to prevent the disease from spreading. Further, Belgium closed its borders, and Trump declared a national state of emergency for the U.S. [29]. On March 23, a Monday, the German federal cabinet approved billions in financial aid as Coronarelief-emergency-package [29]. The last outlier, April 8 , is characterized by Trump's threat to stop payments to the WHO as he accused it of not having disclosed information on the pandemic early enough [29].

We performed the cleaning of the Twitter corpus before topic modeling (Figure 3) [30]. Following [1], hashtags and mentions were kept, so those trending topics (identified through hashtags) and prominent users (through their mentions) remain. We used the snowball, snowball-iso, and nltk libraries a custom stop words. The latter hold terms directly referring to 
the virus, like "SARS-Cov-2" and emoticons that were not removed in prior cleaning. While [31] find that the results' quality decreases when stemming, we found it to improve our model performance. The stemmed model provides fewer residuals, higher held-out likelihood, and a lower bound. Solely the semantic coherence decreases slightly with stemming.

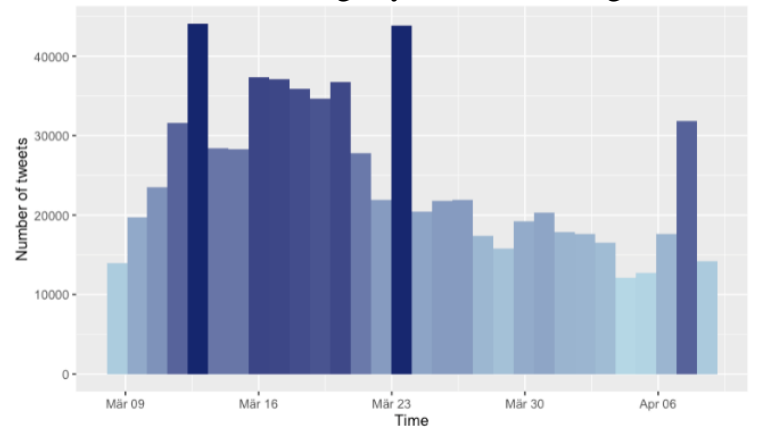

Figure 2. Distribution of the German language tweets during first COVID-19 wave $(n=742,467)$

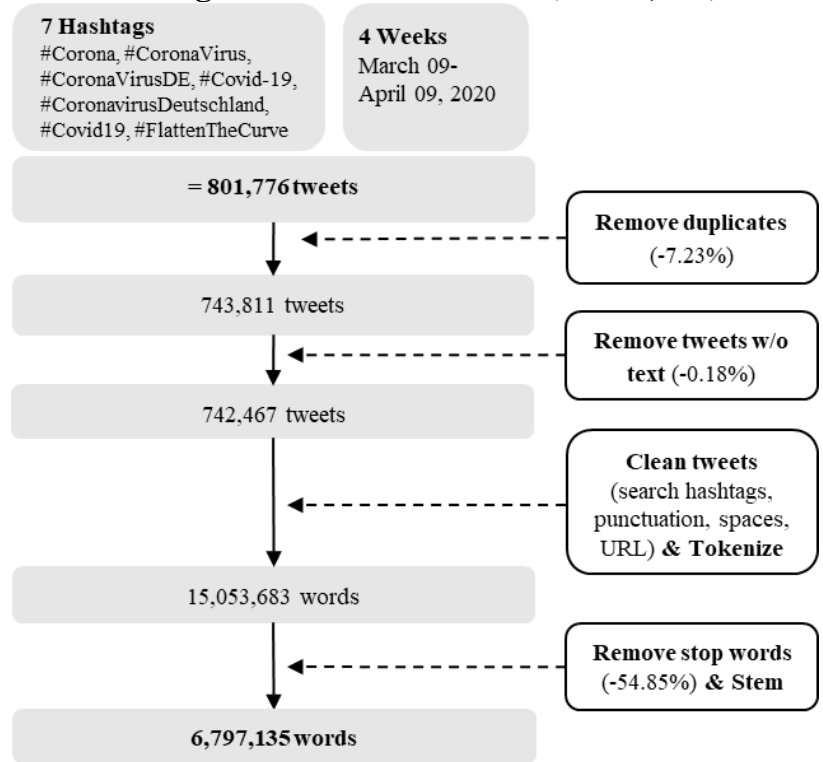

Figure 3. Data cleaning process

To extract topics, we chose an unsupervised machine learning approach - the structural topic model (STM), which allows for variation in topic proportions and word distribution and, most importantly, incorporates covariates [32][48]. The core parameter in STMs is the number of topics $k$ to be detected within a corpus. We analyzed a random one-percent sample of our corpus with $2,3,4,5,10,15,20,30,40,60$, and 80 topics using the stm package [32] to find the best fitting model. The statistical validation step yielded the best models with 15 or 20 topics. In the qualitative validation step, for $\mathrm{k}=15$ and $\mathrm{k}=20$, two researchers inspected the top 10 most probable terms of each topic (based on the per-document-per-topic probabilities, a.k.a. the $\gamma$-values), produced by STM, independently. Inter-rater reliability before the discussion measured with Krippendorff's alpha $(\alpha=0.724)$ was acceptable. After the discussion, a consensus was reached. For the model with 20 topics, results were much more difficult to interpret, which supported the decision of selecting $\mathrm{k}=15$. To sum up, the model with 15 topics was chosen; the topics were labeled and then matched to the coping \& regulatory foci framework in Figure 1.

\section{Results}

\subsection{Twitter content in the total timeframe}

To answer our RQ1, i.e., to analyze public reactions to the pandemic in terms of coping and motivation, we classified the topics according to the four clusters of the coping \& regulatory foci framework (Table 1). The originally obtained most probable terms and the exemplary tweets were translated from German into English for better readability and consistency throughout the paper.

Understanding (Problem - Promotion). The problem-promotion approach, which includes information-seeking and sharing, is the dominating public reaction in our Twitter corpus, with $37 \%$ of topics belonging to this category. Twitter users seek to close knowledge gaps and persuade peers to increase the level of literacy about COVID-19 and possible treatments. Topics range from a general update on the situation to information on the global and local spread of the virus. Accounting for fast contagion, tweets like "Current information about \#Corona in \#Mannheim" or "The state of NRW today decided on further measures to combat the \#Coronavirus" dominate the conversation. Further, Twitter users talk about the increasing number of infections and are concerned with canceling events. Especially football events are discussed - "What's the future of the \#Bundesliga in times of \#Corona?" Users explicitly call for sharing and reading news and publish sources themselves for further education. Reliable advice of doctors, Ph.D.'s and virologists is preferred. Christian Drosten, head of virology at the Berlin university campus Charité, provides expert knowledge and has gained substantial reach during this pandemic [33]. Exemplary tweets are: "For those who want to get scientific \& informative information about the \#CoronaVirus, you should listen to the \#CoronaVirusUpdatePodcast with @c_drosten" or "Informing helps right now. Christian Drosten enlightens. Currently probably the best source for serious information. Please be considerate and inform yourself. Thank you \& good health to you all!" 
Table 1. Matching topics with labels and behavioral patterns according to coping \& regulatory foci framework

\begin{tabular}{|c|c|c|c|c|c|c|}
\hline Label & $\begin{array}{l}\text { Coping } \\
\text { Focus }\end{array}$ & $\begin{array}{l}\text { Regulatory } \\
\text { Focus }\end{array}$ & Topic & $\begin{array}{l}\text { Topic } \\
\text { prop. }\end{array}$ & Ten most probable terms & Example Tweets \\
\hline \multirow{6}{*}{$\begin{array}{l}\text { Understan- } \\
\text { ding }(37 \%)\end{array}$} & Problem & Promotion & Update & $9 \%$ & $\begin{array}{l}\text { current, ask, important, find, } \\
\text { topic, information, info, } \\
\text { situation, status, due to }\end{array}$ & $\begin{array}{l}\text { "Current information about \#Corona in } \\
\text { \#Mannheim" or "Information about the Corona } \\
\text { situation and the effects on us and our industry." }\end{array}$ \\
\hline & Problem & Promotion & $\begin{array}{l}\text { Global } \\
\text { magnitude }\end{array}$ & $8 \%$ & $\begin{array}{l}\text { germany, country, italy, de, } \\
\text { \#merkel, german, china, dead, } \\
\text { europe, usa }\end{array}$ & $\begin{array}{l}\text { "While Germany steals equipment from } \\
\text { Switzerland, China sends masks to Italy" or "We } \\
\text { can see in China and Italy how fast the spread is } \\
\text { progressing." }\end{array}$ \\
\hline & Problem & Promotion & Infections & $7 \%$ & $\begin{array}{l}\text { case, number, infected, update, } \\
\text { person, \#germany, infection, } \\
\text { positive, patient, tested }\end{array}$ & $\begin{array}{l}\text { "New figures from RKI: My report today on the } \\
\text { situation in Germany. Further strong increase in } \\
\text { case numbers + rising case mortality" or } \\
\text { "Coronavirus in the Rhein-Sieg district: number of } \\
\text { infections continues to rise. } 260 \text { tested positive } \\
\text { \#SarsCoV2." }\end{array}$ \\
\hline & Problem & Promotion & News & $5 \%$ & $\begin{array}{l}\text { please, read, \#trump, article, } \\
\text { share, pleasure, listen, bild, } \\
\text { interesting, usa }\end{array}$ & $\begin{array}{l}\text { "\#Doctors and the \#coronavirus, an article worth } \\
\text { reading for better understanding." }\end{array}$ \\
\hline & Problem & Promotion & $\begin{array}{l}\text { Changing the } \\
\text { event format to } \\
\text { online, shift or } \\
\text { cancellation }\end{array}$ & $4 \%$ & $\begin{array}{l}\text { match, cancelled, event, } \\
\text { cancellation, \#bundesliga, } \\
\text { postpone, take place, football, } \\
\text { offer }\end{array}$ & $\begin{array}{l}\text { "Due to cancellation of the bookfair because of } \\
\text { \#Corona, we are now online for everyone via } \\
\text { @zoom_us" or "What's the future of the } \\
\text { \#Bundesliga in times of \#Corona?" }\end{array}$ \\
\hline & Problem & Promotion & $\begin{array}{l}\text { Education, } \\
\text { expert } \\
\text { explanation of } \\
\text { about pandemic }\end{array}$ & $4 \%$ & $\begin{array}{l}\text { \#pandemic, explained, video, } \\
\text { dr, interview, \#virus, talks, } \\
\text { @youtub, phd, virologist }\end{array}$ & $\begin{array}{l}\text { "For those who want to get scientific \& informative } \\
\text { information about the \#CoronaVirus, you should } \\
\text { listen to the \#CoronaVirusUpdatePodcast with } \\
\text { @c_drosten" or Informing helps right now. } \\
\text { Christian Drosten enlightens. Currently probably } \\
\text { the best source for serious information." }\end{array}$ \\
\hline \multirow{3}{*}{$\begin{array}{l}\text { Action } \\
\text { planning } \\
(23 \%)\end{array}$} & Problem & Prevention & Local measures & $8 \%$ & $\begin{array}{l}\text { measure, test, austria, spread, } \\
\text { government, switzerland, } \\
\text { mask, boarder, country, curfew }\end{array}$ & $\begin{array}{l}\text { "The state of North Rhine-Westphalia today } \\
\text { decided on further measures to combat the } \\
\text { \#Coronavirus." }\end{array}$ \\
\hline & Problem & Prevention & Staying home & $11 \%$ & $\begin{array}{l}\text { \#stayhome, \#westayhome, } \\
\text { home, school, child, } \\
\text { \#homeoffice, stays, closed, } \\
\text { already, week }\end{array}$ & $\begin{array}{l}\text { "Hey folks, I'm also home a lot right now to protect } \\
\text { myself and others" or "Day } 10 \text { \#HomeOffice with } \\
\text { two small children." }\end{array}$ \\
\hline & Problem & Prevention & Compliance & $4 \%$ & $\begin{array}{l}\text { live, berlin, police, \#berlin, } \\
\text { public, \#police, app, pandemic, } \\
\text { rules, dortmund }\end{array}$ & $\begin{array}{l}\text { "PLEASE take the instructions of the authorities } \\
\text { seriously - now avoid all public places. The elderly } \\
\text { among us will thank you, and so will the police!" }\end{array}$ \\
\hline \multirow{3}{*}{$\begin{array}{l}\text { Hope } \\
(18 \%)\end{array}$} & Emotion & Promotion & $\begin{array}{l}\text { Support \& } \\
\text { gratitude for } \\
\text { helpers }\end{array}$ & $7 \%$ & $\begin{array}{l}\text { work, help, company, helps, } \\
\text { support, medical, money, } \\
\text { medicine, cooperation, fast }\end{array}$ & $\begin{array}{l}\text { "State government promises companies necessary } \\
\text { support" or "The protective shield must come now. } \\
\text { Nursing staff, doctors and therapists need the } \\
\text { approval now" or "Merkel to doctors and nursing } \\
\text { staff: 'What you are doing is incredible!" }\end{array}$ \\
\hline & Emotion & Promotion & $\begin{array}{l}\text { Solidarity \& } \\
\text { empathy to } \\
\text { people at higher } \\
\text { risk }\end{array}$ & $7 \%$ & $\begin{array}{l}\text { stay, healthy, old, protect, } \\
\text { home, stop, beloved, contact, } \\
\text { social, young }\end{array}$ & $\begin{array}{l}\text { "According to virologist Christian \#Drosten from } \\
\text { the Berlin \#Charité, older people need special } \\
\text { protection" or "There is a strong appeal for } \\
\text { solidarity, especially among younger people, to } \\
\text { protect the elderly." }\end{array}$ \\
\hline & Emotion & Promotion & Duration & $4 \%$ & $\begin{array}{l}\text { time, week, after, pandemic, } \\
\text { months, give, news, difficult, } \\
\text { long, despite }\end{array}$ & $\begin{array}{l}\text { "Hopefully the virus will not persist" or } \\
\text { "Coronavirus: 'In extreme cases, restrictions could } \\
\text { last two years." }\end{array}$ \\
\hline \multirow{3}{*}{$\begin{array}{l}\text { Reassu- } \\
\text { rance } \\
(22 \%)\end{array}$} & Emotion & Prevention & $\begin{array}{l}\text { Questioning the } \\
\text { outcome }\end{array}$ & $7 \%$ & $\begin{array}{l}\text { crisis, economy, corona crisis, } \\
\text { consequence, together, politic, } \\
\text { demand, state, \#eu, \#afd }\end{array}$ & $\begin{array}{l}\text { "Our goal is that all companies and businesses get } \\
\text { through this crisis safely, "says @OlafScholz" or } \\
\text { "The economy groans and moans - \#Corona crisis." }\end{array}$ \\
\hline & Emotion & Prevention & Anxiety & $10 \%$ & $\begin{array}{l}\text { simply, people, actually, } \\
\text { danger, fear, exactly, know, } \\
\text { believe, say, terrible }\end{array}$ & $\begin{array}{l}\text { "Are you afraid of the \#Coronavirus?" or "More } \\
\text { and more people are afraid, don't feel safe." }\end{array}$ \\
\hline & Emotion & Prevention & Panic buying & $5 \%$ & $\begin{array}{l}\text { concern, toiletpaper, grocery } \\
\text { shopping, word, de, } \\
\text { supermarket, empty, buy, } \\
\text { \#toiletpaper, get }\end{array}$ & $\begin{array}{l}\text { "I'm curious what happens if it turns out that toilet } \\
\text { paper doesn't help against the virus at all" or } \\
\text { "\#ShowYourCharacter in the \#Supermarket: Don't } \\
\text { hoard and only buy what you need." }\end{array}$ \\
\hline
\end{tabular}


Action planning (Problem - Prevention). With a topic proportion of $23 \%$, "Action planning" captures the courses of action to prevent the crisis's worsening and ranks second in popularity as expressed in the online German-speaking space. This category encompasses "Staying at home," a single most discussed topic in our Twitter corpus (11\%). The movement of social distancing classifies as pro-social behavior as it is a commonly acknowledged measure to contain the virus and thus to protect groups at risk like the elderly or people with pre-existing conditions. Additionally, local decisions and general compliance with the rules as implemented by the government and enforced by the police are discussed, for example: "PLEASE take the instructions of the authorities seriously - now avoid all public places."

Hope (Emotion - Promotion). The third cluster, calling for the activation of positive emotional resources that help to stand the crisis, was slightly less famous in our Twitter corpus (18\%). The topics appeal to respect and thoughtfulness and are mainly addressed to younger people and their behavior towards the elderly, not to act inconsiderately. While youngsters might not show symptoms of the disease, they can contribute to dissemination. As one Twitter user puts it: "There is a strong appeal for solidarity, especially among younger people, to protect the elderly." The topic labeled "Support \& gratitude for helpers" $(7 \%)$ highlights the medical and health care workers that are working additional shifts and overtime - their efforts and service to the public are widely recognized [34].

Reassurance (Emotion - Prevention). The fourth cluster, labeled "Reassurance," which unites the expressions of negative emotions like anxiety and frustration as well as corresponding actions, is widely present among the German-speaking public and occupies $22 \%$. The main topic points out worries related to grieving and questing for meaning, disbelief, and shock. "Anxiety" with the proportion of $10 \%$ scores as the second-largest single topic, after "Staying home" (11\%). In these tweets, users express their fear, stress, and concerns regarding COVID-19 due to its quick dissemination and the lack of treatments or vaccines. Emotional stress often results in panic behavior, which, in turn, meets public critique. Moreover, according to [35], people exhibit less tolerance towards differing views, face people with greater bias and prejudiced attitudes and engage in more stereotyping when confronting inner terror such as the pandemic [35]. On Twitter, the phenomenon of buying toilet paper or canned food is met with great irony, judging people that buy out supermarkets. Few fear the lack of an adequate supply of essential goods. Tweets say, „\#ShowYourCharacter in the \#Supermarket: Don't hoard and only buy what you need" or "I'm curious what happens if it turns out that toilet paper doesn't help against the virus at all."

\subsection{Inter-temporal analysis of topic proportions}

As the second part of our research agenda, we investigate whether topics and their respective proportions will change over time. With our research period compromising four and a half calendar weeks (CW), we ran five STMs each week independently to evaluate changes in relative proportions. The sample size for each week comprised $\mathrm{N}_{\mathrm{CW} 10}=33,593$ tweets; $\mathrm{N}_{\mathrm{CW} 11}=230,437$ tweets; $\mathrm{N}_{\mathrm{CW} 12}=200,886$ tweets; $\mathrm{N}_{\mathrm{CW} 13}=136,886$ tweets; $\mathrm{N}_{\mathrm{CW} 14}=111,278$ tweets, and $\mathrm{N}_{\mathrm{CW} 15}=29,346$ tweets.

Generally, we observed high variability in topic proportions (Figure 6). As such, tweets concerning the topic "Cancellation of events" (problem-promotion cluster) only appear in the first week. Similarly, "Panic buying" (emotion-prevention cluster)- discussion on hoarding food, purchasing large quantities of toilet paper, long-lasting grocery, and facing empty supermarkets happens within the first two weeks, not re-appearing again. Topic proportions in "Compliance" (problem-prevention cluster) also evidence high volatility, appearing in the corpus every second week. Tweets on "Support and gratitude for helpers" (emotion-promotion cluster) appear in the beginning and at the end of our research timeframe while not emerging from the data in calendar week 13 (CW13) and 14 (CW14).

Few topics remain prominent throughout the whole research period. "Staying home" (problemprevention cluster) is highly discussed each week, except for CW14. It can be explained by the fact that social distancing is widely practiced and an easy way to contain the virus. Companies encourage or mandate work-from-home, and with schools and daycare closed, the majority of the German population spends their time at home. Further, close monitoring of the number of infections (problem-promotion cluster) remains constantly active. Here, topic proportions fall between 8 to $14 \%$ percent, peaking in CW13. Interestingly, the dynamics of the topics "News" and "Education" are the opposite. While Twitter users refer to scientific information sources in the rise of COVID-19, general news outlets are preferred as time passes. As the pandemic progresses and it becomes more and more apparent that the disease persists, an increasingly high number of tweets is concerned with the crisis duration or the current state, thus turning from problem-based to emotion-based coping. 


\section{Coping focus}

Problem
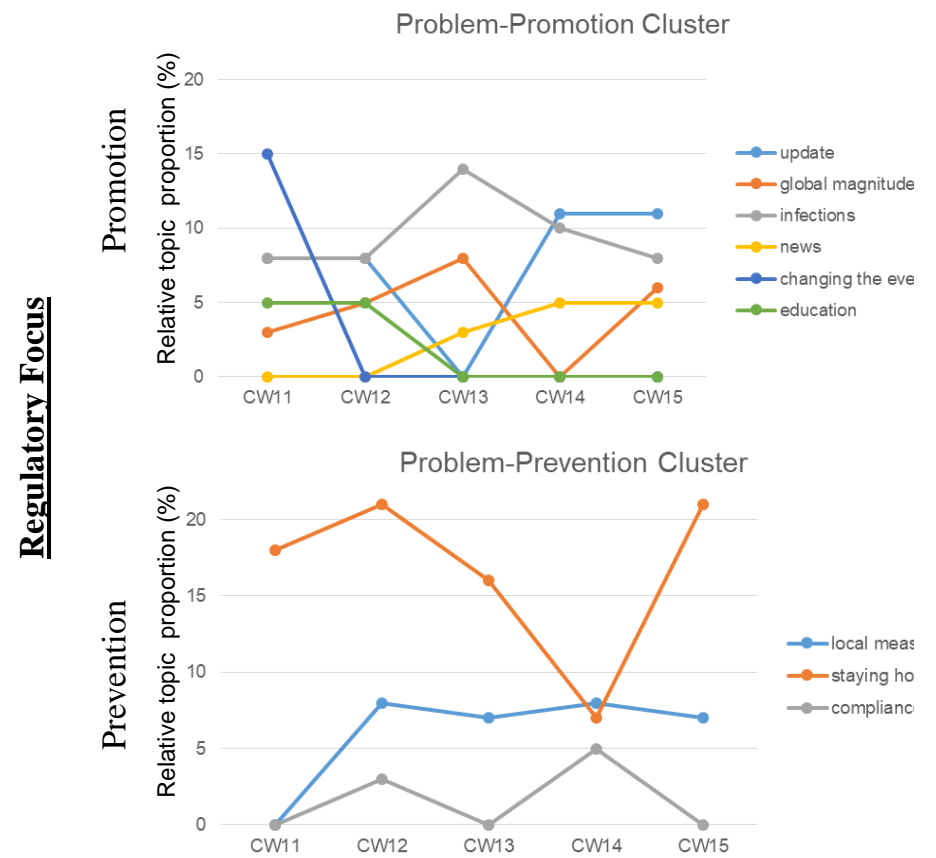

Emotion
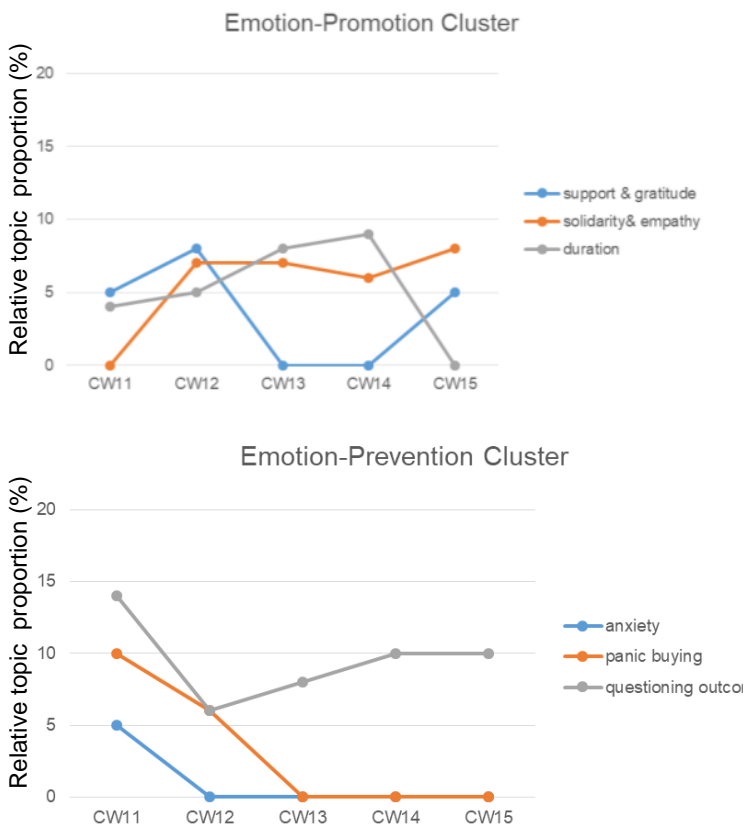

Overall Intertemporal Changes

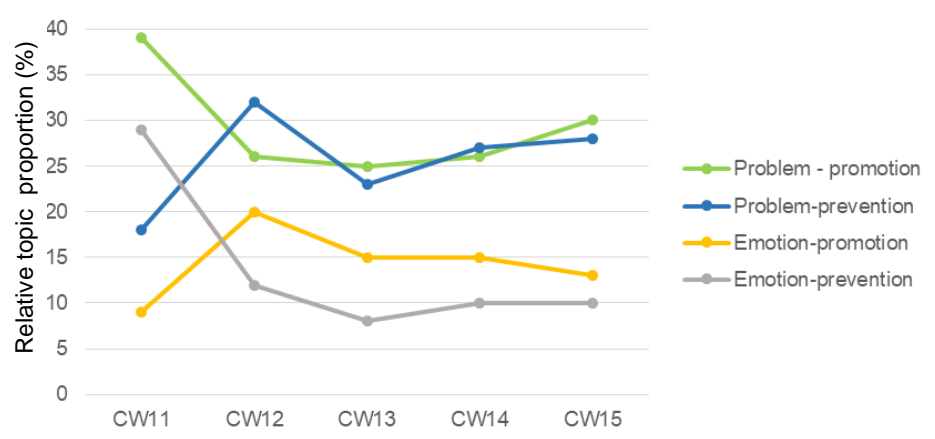

Figure 6. Temporal development of topic proportions

\section{Discussion}

The purpose of our study was to identify common public reactions (RQ1) and inter-temporal topical patterns (RQ2) in Tweets at a collective level during a crisis event. Data from 743,811 unique publicly available tweets among the German-speaking community during the COVID-19 pandemic suggests that the coping and regulation foci framework holds good explanatory power, with four clusters remarkable in public reactions: 1) "Understanding" (problempromotion); 2) "Action planning" (problemprevention); 3) "Hope" (emotion-promotion) and
4) "Reassurance" (emotion-prevention). In the sample, we observe slight dominance of problem-focused $(60 \%)$ vs. emotion-focused $(40 \%)$ reactions. In terms of motivation, public opinion looks nearly balanced, with $55 \%$ being promotion-focused and $45 \%$ preventionfocused. The topics change over time, and the problemoriented clusters prevail over emotion-focused.

\subsection{Research Implications}

We believe our investigation is novel and important because it adds new findings on crisis management using social media [52], contributing to existent research in several ways. First, we address the need to 
understand the public mood and motivations dominating in the online response to a crisis event (in this particular case, the COVID-19 pandemic) by complementing a widely applied distinction in coping foci (problemfocused vs. emotion-focused) with regulatory focus theory (promotion-focused vs. prevention-focused). In this regard, our paper complements the few studies that explore how individuals use social media in hard times, mainly in the aftermath of human-made terror in the form of terrorist attacks, shootings, or bombing [10][36][37].

Prior research scrutinized behavior under the assumption that when facing a severe problem, people are lost and lean on sensemaking [2] or terror management [1]. We observe that the topics in our Twitter corpus do not match well with typical terror management distal reactions as introduced by [38] and [35] and verified by [1]. In turn, we got inspired by the novel concept of goals associated with health information seeking (GAINS) [12] and applied it to the large-scale sample of tweets containing Coronavirusrelated hashtags. Our study shows that four clusters are salient in public reactions with the corresponding proportions: 1) Understanding (problem-promotion) (37\%); 2) Action planning (problem-prevention) (23\%); 3) Hope (emotion-promotion) (18\%) and 4) Reassurance (emotion-prevention) (22\%). Thus, our work may serve as additional evidence for the GAINS instrument's construct validity, previously tested only based on the psychometric properties using surveys.

The dominance of the "Understanding" cluster suggests users mainly turn to social media as essential information sources. As most individuals in Germany do not have prior experience with pandemics, information gathering is critical to comprehend the situation and cognitive bridge gaps [11]. Further, Twitter, by definition, is an instant information-sharing network designed to facilitate easy and fast dissemination of news, which might be the reason for the results to display relatively high shares of information communication compared to other SNS or personal communication [10][39]. Interviewing individuals in the aftermath of 9/11, [38] also report a prevalence of information seeking and sharing with around $20 \%$ share. Prior studies related to Twitter information flow in pandemics were done during the 2019 Ebola outbreak. Mining tweets on an Ebola live chat returned information sharing categories such as modes of contraction and on the virus itself [3]. During the $2009 \mathrm{H} 1 \mathrm{~N} 1$ outbreak, tweets were primarily used to disseminate information from credible sources, personal experiences, and opinions, and the topic category displayed a relative proportion of $52.6 \%$ with regards to remaining topics [40]. Our findings also accord with [1], where the sensemaking theme "Information seeking and sharing," which translated operation updates and special broadcasts, was the primary distal reaction with the share of $47.8 \%$.

Reflected in the "Action planning" cluster, since the disease severely threatens especially the old and chronically ill people, Twitter users encourage each other to engage in social distancing and tweet from home. Posts might read: „Hey folks, I'm also home a lot right now to protect myself and others." Because the crisis requires a large-scale behavioral change to contain the virus, large-scale campaigning is conducted by officials to encourage pro-social behavior; this includes, among others, keeping distance or wearing face masks [41]. [42] show that public health information is especially relevant to ensure sustained changes in lifestyle behaviors during a prolonged outbreak, especially when severity appears to be declining.

In the emotion-focused domain, unfortunately, negative reactions prevail, with the cluster "Reassurance" accounting for adverse states like anxiety and panic, overperforming the cluster "Hope" promoting positive senses. The topic "Questioning the outcome" (7\%) corresponds to the findings on the "Swine flu" outbreak in 2009, where the authors spotted that Twitter users will frequently talk about the economic and social effects of the virus [40]. While many people in Germany thanked the helpers like nursing staff and doctors, and retail employees offline with multiple applause from the balcony or via street flash mobs [43], similar reactions are expressed online from time to time (7\%). Still, the dedication in our sample can be considered as significant, exceeding the similar topic in work by [1] (namely, "Gratitude for helpers associated with the attacks" $2.8 \%$ ) by nearly four percent.

In line with prior research, the inter-temporal analysis suggests priorities' variation throughout the health crisis. This finding corresponds well with the observation of [40] on varying topics in Twitter discussions on the H1N1 virus. Further, comparing events that took place during our research period to the topics uncovered for the same time frame, we find that external events have a strong influence on topical prevalence. In March 2020, Twitter users were most concerned with the immediate consequences like the cancellation of events. This might well be connected to the announcement of several large organizations to cancel or postpone booked services. On March 13th, the German Football League announced to suspend all matches immediately; Lufthansa had released a statement to cancel around 23,000 flights two days earlier, on March 11th [44][45]. Topics associated with mid-and long-term effects and consequences of the crisis, like economic consequences, social distancing 
behavior, or infections, remain constant in their appearance.

Moreover, we observe a shift from self-centered to community-centered topics over the course of four and a half weeks. As risk perception of the virus changes with time, so does individuals' behavior [46]. In CW11 and CW12, Twitter users express engaging in superficially protective behavior of buying more food or toilet paper in higher than usual quantities [46]. With risk perception decreasing over time, we can observe that panic buying gives way to solidarity and empathy. Luckily, contrary to [1], reactions such as nationalistic sentiment or its counterpart, counter-bigotry activism, which is the core of terror management theory, are not salient in our Twitter corpus. We do not find any indication that fake news distorted the results of our topic modeling.

\subsection{Practical Implications}

For practitioners, our study illustrates the potential of social media text mining to extract public opinions and reactions quickly and efficiently. Monitoring fears and trending topics enable policymakers to rapidly respond to deviant behavior, like resistive attitudes towards containment measures or deteriorating physical health [47]. Healthcare workers can use the insights to provide mental health services for battling anxiety or extensive loneliness from staying home. As an unsupervised machine learning approach, the STM enables analysis and interpretation of electronic text at scale, which would not be possible by the human notation [40][49]. Topic modeling is of interest to any stakeholder who wishes to gain insight from textual data to understand what is being discussed online. Understanding an individual's motivation to interact on SNS in times of health crisis events, SNS companies like Twitter will want to ensure that people can easily access their sites and communicate with peers according to their needs. For example, Facebook implemented the Safety Check feature and an option to donate [50]. Thus, insights from our topic model might help social network providers to improve their services.

\subsection{Limitations and Future Research}

First, our sample contains tweets with Coronavirusrelated hashtags, thus disregarding posts about pandemics without hashtags. Second, the framework used does not account for fake news. Third, analytically, besides inter-temporal changes reported, covariates on time of posting, the number of likes, or hashtags could additionally be incorporated in the topic model [32]. Since STM is best suitable for texts with a consistent structure that are not too short (like tweets) [48], the consistency of findings can be checked with another ML approach. Next, to broaden the perspective, other SNSs like Instagram and Facebook are to be considered. Future research can analyze how platform-specific features might influence people's online behavior in times of health crisis. While we focused on Germanspeaking tweets, it would be interesting to test whether topics and reactions vary across different cultures and languages. Finally, it seems promising to compare countries with previously experienced large-scale epidemics such as Ebola with states for which COVID19 is the first recent health crisis.

\section{References}

[1] Fischer-Preßler, D., Schwemmer, C. \& Fischbach, K., 2019. Collective sensemaking in times of crisis: Connecting terror management theory with Twitter user reactions to the Berlin terrorist attack. Computers in Human Behavior, Issue 100, pp. 138-151.

[2] Stieglitz, S., Bunker, D., Mirbabaie, M. \& Ehnis, C., 2017. Sensemaking in social media during extreme events. Journal of Contingencies and Crisis Management, 26(1), pp. 4-15.

[3] Lazard, A. J. et al., 2015. Detecting themes of public concern: A text mining analysis of the Centers for Disease Control and Prevention's Ebola live Twitter chat. American Journal of Infection Control, pp. 1-3.

[4] Imran, M., Castillo, C., Diaz, F., \& Vieweg, S. 2015. Processing social media messages in mass emergency: A survey.ACM Computing Surveys (CSUR),47(4),1-38.

[5] Euronews.com, 2021. COVID-19: Protests across Europe rail against pandemic restrictions as infections soar [Online] Available at: https://www.euronews.com/2021/03/21/covid-19protests-across-europe-rail-against-pandemic-restrictions-asinfections-soar

[6] Ehnis, C., Mirbabaie, M., Bunker, D., \& Stieglitz, S. 2014. The role of social media network participants in extreme events. In 25th Australian conference of information systems.

[7] Tye, M., Leong, C., Tan, F., Tan, B., \& Khoo, Y. H. 2018. Social media for empowerment in social movements: the case of Malaysia's grassroots activism. Communications of the Association for Information Systems, 42(1), 15.

[8] Chen, E. \& Lerman, K. F. E., 2020. \#COVID-19: the first public coronavirus Twitter dataset. JMIR Public Health and Surveillance, 6(2).

[9] Scanfeld, D., Scanfeld, V. \& Larson, E. L., 2010. Dissemination of health information through social networks: Twitter and antibiotics. American journal of infection control, 38(3), pp. 182-188.

[10] Heverin, T. \& Zach, L., 2011. Use of microblogging for collective sensemaking during violent crises: a study of three campus shootings. Journal of the Association for Information Science and Technology, 63(1), pp.34-47.

[11] Maitlis, S. \& Christianson, M., 2014. Sensemaking in organizations: taking stock and moving forward. The Academy of Management Annals, 8(1), pp. 57-125.

[12] Chasiotis, A., Wedderhoff, O., Rosman, T., \& Mayer, A. K. (2020). Why do we want health information? The goals associated with health information seeking (GAINS) questionnaire. Psychology \& health, 35(3), 255-274.

[13] Lambert, S. D., \& Loiselle, C. G., 2007. Health information seeking behavior. Qualitative Health Research. 17(8), pp. 10061019.

[14] Higgins, E. T., 1997. Beyond pleasure and pain. American Psychologist, 52(12), pp. 1280-1300. 
[15] Lazarus, R. S., \& Folkman, S., 1984. Stress, appraisal, and coping. New York: Springer Publishing Company.

[16] Folkman, S. \& Lazarus, R. S., 1980. An analysis of coping in a middle-aged community sample. Journal of Health and Social Behavior. 21(3), pp. 219-239.

[17] Carroll, L., 2013. Problem-focused coping. Encyclopedia of behavioral medicine, pp. 1540-1541.

[18] Cheng, S. T., Tsui, P. K., \& Lam, J. H., 2015. Improving mental health in health care practitioners: Randomized controlled trial of a gratitude intervention. Journal of consulting and clinical psychology, 83(1), 177.

[19] Bergvik, S., Sørlie, T., \& Wynn, R., 2010. Approach and avoidance coping and regulatory focus in patients having coronary artery bypass graft surgery. Journal of Health Psychology, 15(6), pp. 915-924.

[20] Dijkstra, A., Rothman, A., \& Pietersma, S., 2011. The persuasive effects of framing messages on fruit and vegetable consumption according to regulatory focus theory. Psychology \& Health, 26(8), pp. 1036-1048

[21] Yi, S., \& Baumgartner, H., 2009. Regulatory focus and message framing: a test of three accounts. Motivation and Emotion, 33(4), 435-443.

[22] Craciun, G., 2018. Choice defaults and social consensus effects on online information sharing: The moderating role of regulatory focus. Computers in Human Behavior, 88, 89-102.

[23] Twitter Developer, 2020. Instant historical access to Tweets.[Online]Available at:https://developer.twitter.com/en/products/tweets/search

[24] RKI, 2020. Coronavirus disease 2019. Daily situation report of the Robert Koch Institute. [Online] Available at: https://www.rki.de/DE/Content/InfAZ/N/Neuartiges Coronavir us/Situationsberichte/2020-03-09en.pdf? blob=publicationFile

[25] RKI, 2020. Robert-Koch-Insitut: COVID-19-Dashboard. [Online] Available at: https://experience.arcgis.com/experience/478220a4c454480e 82 $3 \mathrm{~b} 17327 \mathrm{~b} 2 \mathrm{bf} 1 \mathrm{~d} 4$.

[26] Ârzteblatt, 2020. COVID-19: Die Hashtags der Krise. [Online] Available https://www.aerzteblatt.de/nachrichten/111302/COVID-19Die-Hashtags-der-Krise.

[27] RND, 2020. Hashtags zu Corona: Soziale Medien helfen in der Krise. [Online] Available at: https://www.rnd.de/digital/diesecorona-hashtags-bieten-hilfe-aus-social-mediaPIDIUFALQVEOLF73CUAM6CP4VU.html

[28] Twitter, 2020. COVID-19 stream. [Online] Available at: https://developer.twitter.com/en/docs/labs/covid19stream/filtering-rules [Accessed 30 May 2020].

[29] Tagesschau, 2020. 365-Tage-Meldungsarchiv. [Online] Available http://www.tagesschau.de/archiv/meldungsarchiv100.html

[30] Maerz, S. F. \& Puschmann, C., 2020. Text as data for conflict research: a literature survey. In: E. Deutschmann, et al. eds. Computational Conflict Research. 1 ed. Cham, Switzerland: Springer Open, 43-65.

[31] Mimno, D. et al., 2011. Optimizing semantic coherence in topic models. EMNLP '11: Proceedings of the Conference on Empirical Methods in Natural Language Processing, 262-272.

[32] Roberts, M. E., Stewart, B. M. \& Tingley, D., 2019. stm: an R package for structural topic models. Journal of Statistical Software, 91(2), 1-41.

[33] Zeit Online, 2020. "We have to bring down the number of cases now. Otherwise we won't be able to handle it". [Online] Available at: https://www.zeit.de/wissen/gesundheit/2020- 03/christian-drosten-coronavirus-pandemic-germanyvirologist-charite [Accessed 23 July 2020].

[34] Gutensohn, D., 2020. Applaus vom Balkon reicht nicht. [Online] Available at: https://www.zeit.de/arbeit/202003/systemrelevante-berufe-coronavirus-pflegekraefte-kassiererwertschaetzung [Accessed 1 August 2020].

[35] Pyszczynski, T., Solomon, S. \& Greenberg, J., 2003. In the wake of 9/11: the psychology of terror. Washington DC: American Psychological Association.

[36] Kwon, H., Chadha, K. M. \& Wang, F., 2013. Proximity and networked news public: structural topic modeling of global Twitter conversations about the 2017 Quebec mosque shooting. International Journal of Communication, Volume 12, 26522675.

[37] Eriksson, M., 2016. Managing collective trauma on social media: the role of Twitter after the 2011 Norway attacks. Media, Culture \& Society, 38(3), 365-380.

[38] Yum, Y.-o. \& Schenck-Hamlin, W., 2005. Reactions to 9/11 as a function of terror management and perspective taking. The Journal of Social Psychology, 145(3), 265-286.

[39] Oh, O., Agrawal, M. \& Rao, R., 2011. Information control and terrorism: Tracking the Mumbai terrorist attack through twitter. Information Systems Frontiers, Volume 13, pp. 33-43.

[40] Chew, C. \& Eysenbach, G., 2010. Pandemics in the Age of Twitter: Content Analysis of Tweets during the 2009 H1N1 Outbreak. PLoS ONE, 5(11), 1-13.

[41] Federal Ministry of Health, 2020. Mit der AHA-Formel durch den Sommer. [Online] Available at: https://www.zusammengegencorona.de/aha/

[42] Wong, L. P. \& Sam, I.-C., 2010. Temporal changes in psychobehavioral responses during the $2009 \mathrm{H} 1 \mathrm{~N} 1$ influenza pandemic. Preventive Medicine, Volume 51, 92-93.

[43] Tagesschau, 2020. Coronavirus: Applaus für die Helfer. [Online] Available at: https://www.tagesschau.de/inland/corona-dankhelfer-101.html

[44] Deutschland.de, 2020. Coronavirus: Latest updates. [Online] Available at: https://www.deutschland.de/en/news/coronavirusin-germany-informations.

[45] Deutschland.de, 2020. Let us explain: Help for the economy. [Online] Available at: https://www.deutschland.de/en/topic/business/corona-and-theeconomy-how-the-german-government-is-helping

[46] Wise, T., Zbozinek, T., Michelini, G. \& Hagan, C. C., 2020. Changes in risk perception and protective behavior during the first week of the COVID-19 pandemic in the United States. Royal Society open science, 7(9).

[47] Bello-Orgaz, G., Jung, J. J. \& Camacho, D., 2016. Social big data: recent achievements and new challenges. Information Fusion, Volume 28, p. 45-59.

[48] Blei, D. M., 2012. Probabilistic topic models. Communications of the ACM, 55(4), pp. 77-84.

[49] Blei, D., Paisley, J. \& Wang, C., 2012. The discrete infinite logistic normal distribution. Bayesian analysis, 7(2), p.235-272.

[50] Facebook, 2020. Crisis response. [Online] Available at: https://www.facebook.com/about/safetycheck/

[51] Bruns, A., Burgess, J., Crawford, K., \& Shaw, F. 2012. Crisis communication on Twitter in the 2011 South East Queensland floods. [Online] Available at: https://eprints.qut.edu.au/48241/

[52] Weller, K., Bruns, A., Burgess, J., Mahrt, M., \& Puschmann, C. 2014. Twitter and society [Digital Formations, Volume 89]. Peter Lang Publishing. 